\title{
DAMPs activating innate and adaptive immune responses in COPD
}

\author{
SD Pouwels ${ }^{1,2,6}$, IH Heijink ${ }^{1,2,6}$, NHT ten Hacken ${ }^{2,3}$, P Vandenabeele ${ }^{4,5}$, DV Krysko ${ }^{4,5}$, MC Nawijn ${ }^{1,2,7}$ and \\ AJM van Oosterhout ${ }^{1,2,7}$
}

Chronic obstructive pulmonary disease (COPD), a progressive lung disease characterized by sustained neutrophilic airway inflammation, is caused by chronic exposure to noxious stimuli, e.g., cigarette smoke. This chronic exposure can induce immunogenic cell death of structural airway cells, inducing the release of damage-associated molecular patterns (DAMPs). Levels of several DAMPs, including S100 proteins, defensins, and high-mobility group box-1 (HMGB1), are increased in extracellular lung fluids of COPD patients. As DAMPs can attract and activate immune cells upon binding to pattern recognition receptors, we propose that their release may contribute to neutrophilic airway inflammation. In this review, we discuss the novel role of DAMPs in COPD pathogenesis. Relevant DAMPs are categorized based on their subcellular origin, i.e. cytoplasm, endoplasmic reticulum, nucleus, and mitochondria. Furthermore, their potential role in the pathophysiology of COPD will be discussed.

\section{INTRODUCTION}

Chronic obstructive pulmonary disease (COPD) is a major cause of morbidity and mortality, with a worldwide prevalence of $9-10 \% .{ }^{1}$ Currently, COPD is the fourth leading cause of death worldwide and it is estimated to become the third leading cause of death by $2030 .^{2}$ The disease is characterized by progressive airway obstruction that is not fully reversible and accelerated lung function decline. Furthermore, COPD is associated with an abnormal inflammatory reaction in the lungs, causing destruction of lung parenchyma (emphysema) and/or chronic bronchitis. ${ }^{3-5}$ A major risk factor for the development of COPD is chronic exposure to noxious particles and gases, e.g., cigarette smoke, coalmining dust, diesel exhaust particles, and fumes from burning biomass fuels for cooking or heating. ${ }^{6}$ The chronic airway inflammation in COPD is characterized by activation of the innate immune system, as defined by increased numbers of innate immune cells like neutrophils, macrophages, natural killer cells, and mature dendritic cells in lung tissue and airway lumen. In addition, the adaptive immune system is activated in COPD, as defined by lung infiltration of $\mathrm{CD} 8^{+} \mathrm{T}$ cells, $\mathrm{B}$ cells, and both the $\mathrm{T}$ helper type 17 and Thelper type 1 types of $\mathrm{CD} 4^{+} \mathrm{T}$ cells, along with a decrease in regulatory $\mathrm{T}$ cells in the airways. ${ }^{5,7,8}$

At present, little is known about the initial steps in the activation of innate and adaptive immune responses observed in COPD. Curtis et al. ${ }^{10}$ postulated that during early stages of COPD, innate immune inflammation increases with the progression of COPD, whereas in more advanced COPD (GOLD stages III and IV) ${ }^{9}$ adaptive T- and B-cell responses become increasingly important for pathologic abnormalities. Although the exact nature of the triggers for these innate and adaptive immune responses is at present largely unknown, we hypothesize that cell damage upon environmental insults is involved (see Figure 1). According to the danger hypothesis of Matzinger, ${ }^{11}$ "danger signals" or damage-associated molecular patterns (DAMPs) from injured cells can alarm the immune system by activation of pattern recognition receptors (PRRs). Cigarette smoke and other noxious gases and particles can

\footnotetext{
${ }^{1}$ Department of Pathology and Medical Biology, Laboratory of Allergology and Pulmonary Diseases, University of Groningen, University Medical Center Groningen, Groningen, The Netherlands. ${ }^{2}$ GRIAC Research Institute, University of Groningen, University Medical Center Groningen, Groningen, The Netherlands. ${ }^{3}$ Department of Pulmonary Disease, University of Groningen, University Medical Center Groningen, Groningen, The Netherlands. ${ }^{4}$ Molecular Signaling and Cell Death Unit, Department for Molecular Biomedical Research, VIB, Ghent, Belgium and ${ }^{5}$ Department of Biomedical Molecular Biology, Ghent University, Ghent, Belgium. Correspondence: AJM van Oosterhout (a.j.m.van.oosterhout@umcg.nl)

${ }^{6}$ The first two authors contributed equally to this work.

${ }^{7}$ These authors contributed equally to this work.
}

Received 3 July 2013; revised 16 August 2013; accepted 27 August 2013; published online 23 October 2013. doi:10.1038/mi.2013.77 


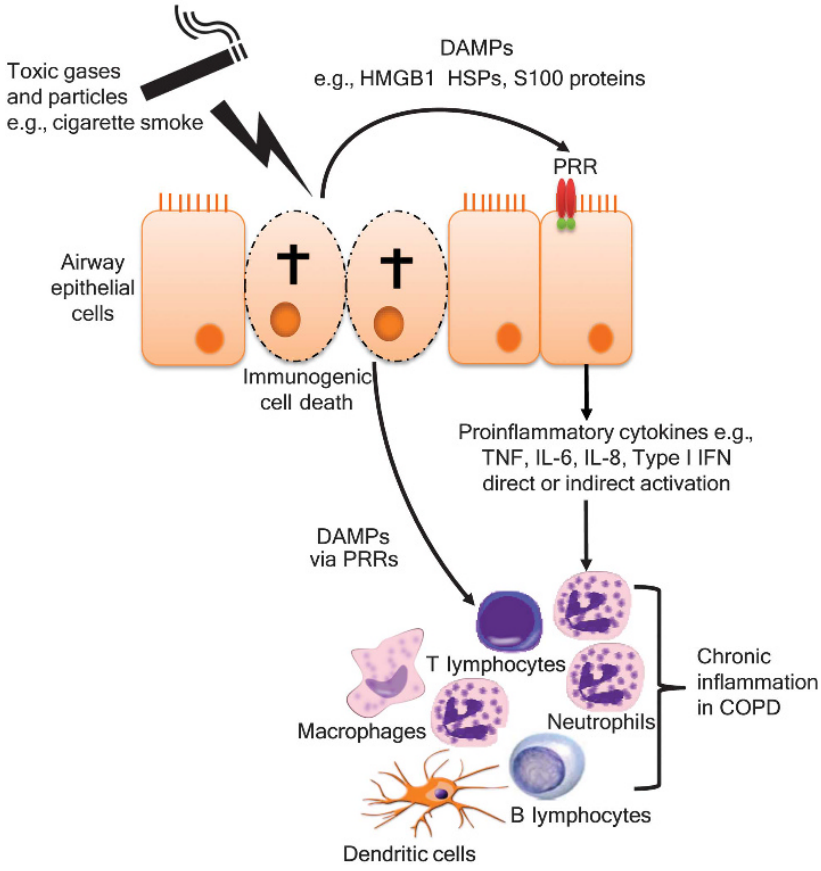

Figure 1 Hypothetical scheme of cigarette smoke (CS)-induced airway epithelial immunogenic cell death followed by damage-associated molecular pattern (DAMP) release and subsequent triggering of the innate and adaptive immune responses in chronic obstructive pulmonary disease (COPD). Inhalation of toxic gases and particles, e.g., cigarette smoke and diesel exhaust particles, causes damage and subsequent cell death to airway epithelial cells. The main immunogenic cell death pathway induced by chronic cigarette smoke exposure is up to date unknown. Upon immunogenic cell death, DAMPs, e.g., high-mobility group box-1 (HMGB1), heat shock proteins (HSPs), and S100 proteins, are released that can activate pattern recognition receptors (PRRs) on adjacent epithelial cells as well as innate and adaptive immune cells. Upon ligation of PRRs, epithelial cells become activated and release proinflammatory cytokines, e.g., tumor necrosis factor (TNF), interleukin (IL)-6, IL-8, and type I interferon (IFN). Proinflammatory cytokines can activate and attract cells of the innate immune system, e.g., neutrophils, macrophages, and dendritic cells, as well as cells from the adaptive immune system, e.g., T lymphocytes and B lymphocytes either in a direct or an indirect manner, e.g., inducing the release of chemokines or upregulating adhesion receptors. Furthermore, DAMPs can also activate and mature cells of the innate as well as the adaptive immune system directly upon binding of PRRs on these cells.

cause damage to resident cells in the lungs, which can induce multiple types of both regulated and nonregulated cell death. ${ }^{12}$ Different forms of cell death, e.g., apoptosis, necrosis (accidental, nonprogrammed), and necroptosis (programmed), may cause distinct signatures of DAMPs released into the extracellular space. ${ }^{13}$ Regulated forms of cell death encompass both apoptosis, a form of programmed and caspase-dependent cell death, and necroptosis, a form of receptor-interacting protein kinase-1 (RIPK1)- and RIPK3-dependent regulated necrosis. Nonregulated cell death encompasses accidental necrosis, where cells when subjected to harsh physicalchemical injuries disrupt through uncontrolled physical events, releasing cellular constituents into the microenvironment. Necrotic and necroptotic cell death are the main but not the only forms of cell death that lead to DAMP release. ${ }^{13,14}$ During early apoptosis, most DAMPs are retained in apoptotic bodies and phagocytized before they can ligate PRRs, yet during secondary necrosis DAMPs can be released. ${ }^{14}$ Secondary necrosis occurs when apoptotic cells are not cleared sufficiently by phagocytosis, such as has been observed in COPD patients. ${ }^{15}$ Recently, it has been shown that disturbances of lung tissue homeostasis, e.g., hypoxia that is seen in COPD patients, also causes immunogenic cell death and subsequent DAMP release. $^{16}$

The airway epithelium forms the first barrier toward inhaled insults, separating lung tissue from the environment. Consequently, epithelial cells are one of the first cells to be exposed to inhaled noxious gases and particles present in cigarette smoke and diesel exhaust fumes. An increase in apoptotic epithelial cells has been shown in the lungs of emphysema patients. ${ }^{17,18}$ Our group has shown that exposure of bronchial epithelial cells to cigarette smoke extract (CSE) causes a switch from apoptotic to necrotic cell death. ${ }^{19}$ Unpublished observations indicate that this switch is in fact a switch from apoptosis to necroptosis. In addition to these direct effects, decreased phagocytosis of apoptotic cells by airway macrophages has also been observed in COPD. ${ }^{15}$ Taken together, these two effects might result in inducing an increased DAMP release in COPD. Some studies show that danger signals released from secondary necrotic cells are often inactivated by caspases, which are expressed during apoptosis and secondary necrosis, resulting in poor immunogenicity of such DAMPs. ${ }^{13,20}$

In addition to the release of DAMPs, cell damage or death also induces the release of several cytokines and chemokines that can induce or regulate immune responses. In particular, interleukin (IL)- $1 \alpha$, IL-6, and IL-33 have been described as danger signals or alarmins, released during immunogenic cell death. ${ }^{21-23}$ Although these ILs can have important proinflammatory properties upon release during accidental necrosis, their function as DAMP is not different from their function under physiological conditions, and therefore the role of ILs in COPD will not be discussed in this review.

As mentioned above, a critical feature of DAMPs is that they specifically bind PRRs, which upon ligation lead to activation of the innate immune system. There are at least five classes of PRRs: Toll-like receptors (TLRs), C-type lectin receptors, NOD-like receptors (NLRs), RIG-I-like receptors, and the receptor for advanced glycation end-products (RAGE), all of which upon ligation activate downstream signaling pathways. These include nuclear factor- $\kappa \mathrm{B}(\mathrm{NF}-\kappa \mathrm{B})$, mitogen-activated protein kinase, and type I interferon pathways, initiating the release of proinflammatory cytokines and chemokines (e.g., IL-6, IL-8, type I interferon, and tumor necrosis factor), and ultimately resulting in activation of the immune system and attraction of immune cells to the site of damage ${ }^{24}$ (see Figure 2). Furthermore, some DAMPs, e.g., heat shock proteins (HSPs), high-mobility group box-1 (HMGB1), galectins, and cathelicidins, can stimulate the adaptive immune system by inducing maturation of dendritic cells upon failure of tolerance mechanisms (e.g., suppression by regulatory $\mathrm{T}$ cells). ${ }^{14}$ Thus, DAMPs can directly activate cells of the innate immune system 


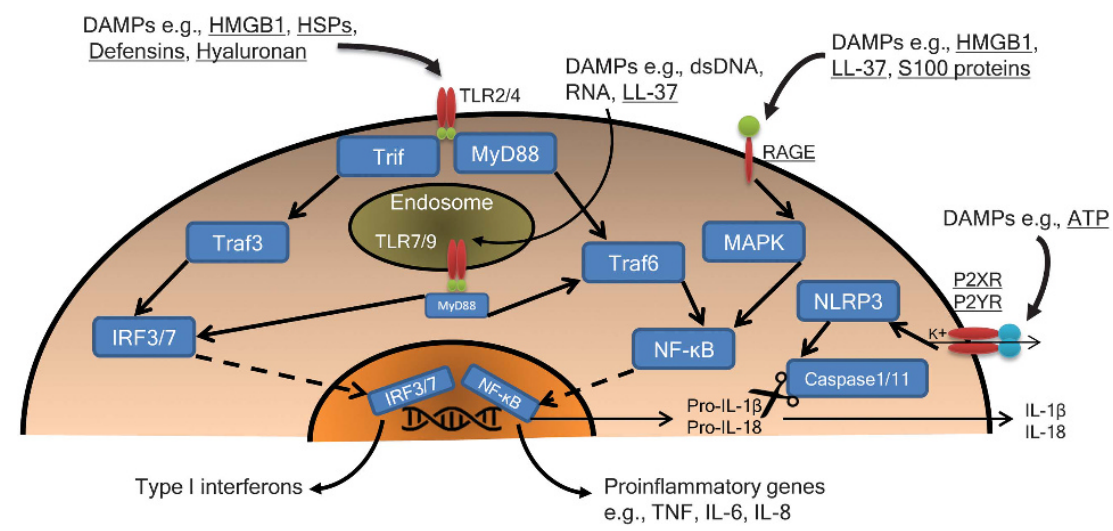

Figure 2 Ligation of pattern recognition receptors (PRRs) by damage-associated molecular patterns (DAMPs), relevant for chronic obstructive pulmonary disease (COPD), initiates the release of proinflammatory cytokines by multiple pathways. Toll-like receptor (TLR)-2/4 receptors can be activated upon binding of DAMPs, e.g., high-mobility group box-1 (HMGB1), heat shock proteins (HSPs), defensins, and hyaluronan, which can cause interferon regulatory factor 3 (IRF3)-mediated release of type I interferons by activation of the Trif/Traf3/IRF3 pathway and subsequent translocation of IRF3 to the nucleus where it initiates transcription of type I interferons. Ligation of TLR2/4 can also cause nuclear factor- $\kappa B$ (NF- $\kappa B$ )-mediated release of proinflammatory cytokines by activation of the MyD88/Traf6/NF- $\kappa B$ pathway and subsequent translocation of NF- $\kappa B$ to the nucleus where it induces transcription of proinflammatory genes, including tumor necrosis factor (TNF), interleukin (IL)-6, and IL-8. TLR-7/9 ligation by DAMPs, e.g., double stranded DNA (dsDNA), RNA, and LL-37, can cause IRF7-mediated release of type I interferons and MyD88/NF- $\kappa$ B-mediated release of proinflammatory cytokines. Ligation of receptor for advanced glycation end-products (RAGE) by DAMPs, e.g., HMGB1, LL-37, and S100 proteins, causes mitogenactivated protein kinase (MAPK)/NF-кB pathway-mediated release of proinflammatory cytokines. Adenosine 5'-triphosphate (ATP) can ligate purine receptors (P2X and P2Y receptors) that cause $\mathrm{K}+$ efflux and subsequent activation of the NLRP3 inflammasome that activates caspase-11 and caspase-1 that, in turn, can cleave Pro-IL-1 $\beta$ and Pro-IL-18, which are transcribed upon NF- $\kappa$ B activation, into their mature forms, after which they will be secreted. DAMPs and receptors underlined in the figure are shown to be upregulated in COPD patients.

and either directly or indirectly promote adaptive immune responses.

To date, no standard classification system for DAMPs is available. In this review we will divide DAMPs into several subclasses based on their main subcellular localization. These subclasses consist of DAMPs derived from the cytoplasm (HSPs, S100 proteins, galectins, antimicrobial peptides), subcellular organelles, i.e., the nucleus (HMGB1), endoplasmic reticulum (ER; calreticulin (CRT), or mitochondria (mitochondrial DNA (mtDNA), N-formylated peptides (NFPs), and adenosine $5^{\prime}$-triphosphate (ATP)), and the extracellular matrix (ECM; versican, fibronectin, hyaluronan). For all these subclasses, specific DAMPs will be discussed with their relation to COPD pathogenesis.

\section{DAMPS DERIVED FROM THE CYTOPLASM Heat shock proteins}

HSPs are prototypical DAMPs derived mainly from the cytoplasm. HSPs are chaperone proteins that are upregulated during various types of physiological and environmental stress conditions, including infections, wounding, or heat. ${ }^{25}$ In physiological concentrations, HSPs act as intracellular molecular chaperones that assist the folding of nascent or misfolded proteins and thereby prevent the aggregation of proteins. ${ }^{25}$ The mammalian HSPs are classified into five different families based on their molecular weight, namely: HSP20, HSP60, HSP70, HSP90, and HSP100. Normally, HSPs are contained intracellularly, but during cellular stress, HSPs are also present at the cell surface or secreted into the ECM. ${ }^{26}$ HSPs released into the extracellular space can function as DAMPs because of their activity as a signaling molecule. Therefore, the term chaperokine was introduced to describe the function of extracellular HSPs. ${ }^{27}$ HSPs have been shown to activate both TLR2 and TLR4 signaling in a MyD88-dependent manner, leading to the initiation of the NF- $\mathrm{kB}$ and interferon regulatory factor signaling pathways, which ultimately leads to the release of proinflammatory cytokines (e.g., tumor necrosis factor, interferons, IL-1 $\beta$, IL-6, and IL-8). ${ }^{25,28}$ Furthermore, HSPs can initiate the maturation and activation of dendritic cells. $^{29}$

The role of HSPs in COPD is not fully elucidated, but in the past few years several studies have been performed to investigate the role of HSPs in COPD and in vitro models. Already in 1997, in vitro studies revealed that HSP70 and HSP90 protein levels are upregulated by cigarette smoke exposure in monocytes. ${ }^{30}$ More recently, it has been shown that the levels of HSP27, HSP70, and HSP90 are significantly higher in the serum of COPD patients compared with nonsmoking individuals. ${ }^{31}$ Furthermore, HSP10, HSP27, and HSP40 protein levels are increased in airway epithelial cells of COPD patients in comparison with healthy controls and control smokers. ${ }^{31}$ In addition, increased HSP60 expression has been observed in bronchial biopsies of patients with severe COPD (GOLD stage III/IV) as compared with healthy nonsmoking volunteers. ${ }^{32}$ This increase in HSP60 was positively correlated with neutrophil numbers in the biopsies, an important pathological hallmark of COPD. Whether this is related to increased extracellular HSP60 levels remains unknown; however, human bronchial epithelial (16HBE) cells actively released HSP60 upon $\mathrm{H}_{2} \mathrm{O}_{2}$ stimulation, to mimic oxidative stress in COPD. ${ }^{32}$ Furthermore, increased release of HSP60 was induced by CSE in human umbilical cord endothelial cell, ${ }^{33}$ indicating that cigarette smoke can induce active secretion of HSP60. 
In conclusion, an increased expression and release of several HSPs has been found in the circulation and lungs of COPD patients. Although some studies only examined intracellular expression of HSPs, increased expression may cause increased release upon accidental necrosis. Further studies are needed to determine whether HSPs may play a causal role in the cigarette smoke-induced neutrophilic airway inflammation and pathogenesis of COPD.

\section{S100 proteins}

S100 proteins are a family of low-molecular-weight calciumbinding proteins. To date, 25 members are known of which S100A8, S100A9, and S100A12 have been recognized as DAMPs. All S100 proteins can form noncovalent homodimers and some, including S100A8/S100A9, can form heterodimers. Intracellularly, S100 dimers interact with downstream effector molecules to regulate cell differentiation and growth, cell attachment, cell cycle progression, and cell motility. ${ }^{34}$ Furthermore, S100 proteins have antimicrobial properties. S100 proteins are expressed in a wide range of cell types, with high constitutive expression of S100A8 and S100A9 in neutrophils of which the cytosolic content consists for $\sim 45 \%$ of S100 proteins. ${ }^{35}$ S100 proteins can be passively released upon accidental necrosis as well as actively secreted by a regulated but unconventional pathway without using a leader sequence for secretion. ${ }^{36}$ Once in the extracellular space, S100 proteins can activate multiple receptors, including RAGE and TLR4, both leading to NF- $\mathrm{KB}$ activation. ${ }^{37}$

Although still largely uncovered, some studies have indicated a role for S100 proteins and their receptor RAGE in the pathophysiology of COPD. Mass spectrometry has revealed that levels of S100A8 and S100A9 are increased in the bronchoalveolar (BAL) fluid of COPD patients in comparison with control smokers and nonsmokers. ${ }^{38}$ Later, a trend toward higher S100A12 levels was observed in the sputum of COPD patients as compared with healthy controls, although the levels of S100A8 and S100A9 were not different between the groups in this study. ${ }^{39,40}$ Furthermore, a recent meta-analysis shows a 1.6-fold increase in S100A12 in the serum of COPD patients as compared with healthy smokers and nonsmokers. ${ }^{41}$ The discrepancy in results between studies can have multiple causes. For instance, studies may differ in their technique to assess S100 proteins, their collection of lung specimen, or in COPD population in characteristics like smoking status and disease severity.

In addition, studies were performed concerning the role of S100 receptor RAGE in COPD, showing an increased expression of RAGE in lung mucosal cells, bronchial epithelial cells, airway smooth muscle cells, and lung macrophages of COPD patients as compared with healthy controls. ${ }^{42}$ In addition, RAGE expression was increased in bronchial epithelial cells and airway smooth muscle cells from COPD patients as compared with control smokers. ${ }^{42}$ Other studies show that levels of soluble RAGE, which blocks binding of ligands to RAGE, are reduced in plasma and BAL fluid of COPD patients as compared with healthy controls. ${ }^{43-45}$
Furthermore, an association has been shown of RAGE with lung function using a genome-wide association study, and RAGE has been proposed as a susceptibility gene for COPD. ${ }^{46,47}$ The combined increase in S100 proteins and RAGE and decrease in soluble RAGE highlights the importance of further studies on the involvement of the S100-RAGE pathway in the pathophysiology of COPD.

\section{Galectins}

Galectins are $\beta$-galactoside-binding lectins that have a variety of physiological functions in humans, including the control of intracellular trafficking of glycoproteins. ${ }^{48}$ Yet, upon release from damaged or dead cells, galectins exhibit a proinflammatory function, qualifying them as DAMPs. ${ }^{48}$ Most galectins are widely expressed in many cell types, including structural and immune cells of the lungs. ${ }^{49}$ Galectins can be secreted both passively upon accidental necrosis and actively by a leaderless secretory pathway similar to the secretion of HMGB1 and S100 proteins. ${ }^{49}$ Galectin-1 and galectin-3 are the most studied galectins and have the strongest reported proinflammatory properties. ${ }^{49}$ The proinflammatory properties of galectin-3 include induction of oxidative bursts in neutrophils, chemoattraction of monocytes, neutrophils, and macrophages, and the induction of IL-8 production by naive and primed neutrophils. ${ }^{50,51}$ For galectin-3, an increase in intracellular protein expression has been observed in the small airways of COPD patients as compared with control smokers and nonsmokers, whereas no significant difference was observed between nonsmoking and smoking controls, suggesting that the increase in galectin-3 is specific for COPD. ${ }^{52}$ Unfortunately, to our knowledge, no studies have been performed studying the levels of galectin-3 in lung fluids.

Similar to galectin-3, increased galectin-1 protein expression has been observed in epithelial cells of the small airways of control smokers in comparison with nonsmokers and COPD patients, yet the levels of COPD patients were still significantly higher than the levels of nonsmokers. ${ }^{52}$ However, the BAL levels of yet another galectin, galectin-9, were not different between COPD patients and healthy controls. ${ }^{53}$ Thus, specifically galectin- 1 and galectin- 3 could contribute to the innate immune response involved in the pathogenesis of COPD, although more research will be required to confirm this.

\section{Antimicrobial peptides}

Antimicrobial peptides derived from the airway epithelium protect the lungs against infections. Some of these antimicrobial peptides can also function as DAMPs. The most well-known antimicrobial peptides with DAMP properties are defensins and cathelicidins. The $\alpha$ - and $\beta$-defensins are expressed in the human lungs and are categorized by their molecular weight and the arrangement of their cysteine disulfide bonds. ${ }^{54}$ Defensins belong to a family of small $(3-6 \mathrm{kDa})$ proteins that share a characteristic $\beta$-sheet and six cysteine residues forming three intrachain disulfide bonds. ${ }^{55}$ Defensins may function as a DAMP by activating TLR4 downstream signaling. ${ }^{56,57}$ In addition, $\alpha$-defensins $1-3$ have chemotactic activity toward monocytes, naive $\mathrm{T}$ cells, and immature dendritic cells. ${ }^{55}$ 
Furthermore, $\alpha$-defensins have been shown to activate the production of proinflammatory cytokines, including IL- $1 \alpha$ and tumor necrosis factor- $\alpha$ by monocytes, leading to the upregulation of adhesion molecules, including intercellular adhesion molecule $1, \mathrm{CD} 11 \mathrm{~b}$, and CD11c by neutrophils. ${ }^{57,58}$ Human $\beta$-defensins 1-2 attract memory T cells, especially of the $\mathrm{T}$ helper type 17 subtype, neutrophils, and immature dendritic cells by binding to the chemokine receptor CCR $6 .{ }^{55,59}$ Furthermore, $\beta$-defensins increase the expression of several proinflammatory cytokines and chemokines (e.g., CXCL5, IL-6, IL-8, monocyte chemotactic protein-1 and granulocyte macrophage colony-stimulating factor) and induce necroptotic cell death. ${ }^{60}$

The concentrations of $\alpha$-defensins 1-3 are higher in the sputum of COPD patients than in nonsymptomatic smokers, and $\beta$-defensin- 1 mRNA expression is significantly higher in bronchial epithelial cells of COPD patients as compared with healthy volunteers. ${ }^{61,62}$ Contradictory findings have been reported on $\beta$-defensin-2 levels in COPD patients. Pace et al. ${ }^{63}$ showed an increased concentration of human $\beta$-defensin- 2 in mini-BAL samples of COPD patients as compared with nonsymptomatic smokers and healthy volunteers, whereas Tsoumakidou et al. ${ }^{64}$ found no detectable levels of human $\beta$-defensin in BAL samples of COPD patients, whereas levels were detectable in control smokers and nonsmokers. Limited data are available from (pre)-clinical studies, where it has been shown that the level of $\beta$-defensin- 2 was increased after cigarette smoke exposure in rats in a NF- $\mathrm{BB}$-dependent manner. ${ }^{65}$ It is noteworthy that COPD patients have a higher bacterial and viral load in their lungs as compared with healthy controls, especially during exacerbations. ${ }^{66,67}$ Although it is possible that increased levels of defensins in COPD patients are a consequence of this increased bacterial load, the increased bacterial load could also be consequence of an impaired antimicrobial response in COPD patients. Nevertheless, the increased $\beta$-defensin levels in COPD do not support the latter and increased $\beta$-defensin release could exert a proinflammatory DAMP function, contributing to the disease pathogenesis.

In addition to defensins, cathelicidins are also antimicrobial peptides with DAMP properties. Cathelicidins are characterized by a highly conserved pre- and pro-region, where the preregion is located at the $\mathrm{N}$-terminus and the pro-region has a structure similar to the cathepsin-L-inhibitor cathalin. At the $\mathrm{C}$-terminus, cathelicidins are very variable. The $\mathrm{C}$-terminus forms the mature peptide with the antimicrobial properties. ${ }^{68}$ LL-37/hCAP-18 is the only cathelicidin that is known to be expressed in humans to date. ${ }^{69}$ LL-37 is expressed by various cell types, including airway epithelial cells, macrophages, lymphocytes, neutrophils, natural killer cells, monocytes, B cells, and mast cells. ${ }^{54}$ Airway epithelial cells are thought to secrete cathelicidins in the airway surface fluid, as LL-37 is found in human BAL fluid and in supernatant of primary bronchial epithelial cell cultures. ${ }^{70,71}$ Cathelicidins have a clear DAMP function, as they can provoke a proinflammatory response through TLR7, TLR9, and RAGE activation, either alone or in complex with extracellular DNA. ${ }^{72-74}$ Furthermore,
LL-37 has chemotactic activity toward eosinophils and neutrophils, which is mediated via the formyl peptide receptor. ${ }^{75}$ LL-37 can also induce necrosis upon stimulation in human airway epithelial cells, although this only occurs when concentrations exceed a certain threshold, rendering the clinical relevance of this finding debatable. ${ }^{76} \mathrm{~A}$ dose-dependent increase in IL-8 release and apoptosis has been observed in airway epithelial cells stimulated with recombinant LL-37. ${ }^{77}$ Furthermore, CSE dose-dependently increased the protein expression of LL-37 in airway epithelial cells. ${ }^{77}$ Multiple studies show that the levels of LL-37 in the sputum of COPD patients during exacerbations as well as in stable disease are significantly higher as compared with smoking and nonsmoking controls. ${ }^{77-79}$ Importantly, this increase in LL-37 levels is inversely correlated with lung function, although further research needs to elucidate whether this is a cause or a consequence of COPD ${ }^{77,79}$ No increase was found in the serum of COPD patients as compared with smoking and nonsmoking controls, ${ }^{77}$ indicating a local increase of LL-37 instead of a systemic increase. Recently, it was shown that LL-37 levels in the BAL fluid and epithelial lining fluid (ELF) of early-stage COPD (GOLD stage I-II) patients were significantly increased as compared with healthy controls. The same study showed that in late-stage COPD (GOLD stage III-IV) patients, the BAL and ELF levels of LL-37 were significantly decreased as compared with healthy controls. ${ }^{80}$ Interestingly, it has been shown that LL-37 can bind extracellular DNA and facilitate binding of DNA to TLR9, inducing a proinflammatory response. ${ }^{73}$ Thus, LL-37 has properties that may be relevant in COPD pathogenesis and higher levels have been observed in extracellular fluids of COPD patients, although it needs to be established whether increased LL-37 levels actually lead to increased airway inflammation in COPD.

\section{DAMPS DERIVED FROM SUBCELLULAR ORGANELLES HMGB1}

One of the most extensively studied DAMPs is HMGB1, a 215 amino-acid nonhistone molecule that is normally resident in the cell nucleus, where it binds DNA to facilitate the assembly of nucleoprotein complexes. ${ }^{81}$ HMGB1 can exert proinflammatory functions when it resides in the extracellular space. ${ }^{82}$ This occurs either when HMGB1 is released actively by a nonconventional secretory mechanism upon stimulation with proinflammatory mediators (e.g., lipopolysaccharide, proinflammatory cytokines, nitric oxide) or passively upon necrosis. ${ }^{83}$ During apoptosis and secondary necrosis, HMGB1 cannot be released because of its irreversible binding to chromatin that undergoes structural modifications upon apoptosis. ${ }^{81}$ This can result from posttranslational modifications, including histone acetylation and DNA methylation. ${ }^{84}$ When HMGB1 is secreted, either passively or actively, it has been demonstrated to bind to different PRRs, including TLR2, TLR4, and RAGE. ${ }^{85,86}$ TLR9 is also mentioned as a receptor for HMGB1, although this is controversial, ${ }^{87}$ as HMGB1 readily forms complexes with various molecules including DNA, a 
known TLR9 ligand, therefore indirect binding of HMGB1 to TLR9 cannot be ruled out. ${ }^{88,89}$ Moreover, HMGB1 exerts direct chemotactic activity toward monocytes, macrophages, neutrophils, and dendritic cells. ${ }^{90}$ Furthermore, HMGB1 can promote the activation, migration, and maturation of dendritic cells. ${ }^{91,92}$ However, there is debate about the direct immunostimulatory properties of HMGB1, as some studies show that highly purified HMGB1 does not exert proinflammatory properties itself, ${ }^{93}$ but that the proinflammatory properties are caused by formation of complexes of HMGB1 with DNA, lipids, lipopolysaccharide, or cytokines. ${ }^{92,94}$ These complexes are possibly highly inflammatory and may stimulate cytokine production via binding of TLRs or IL-1 receptor. The fact that other studies have shown an immunostimulatory effect of purified HMGB1 may be explained by lipopolysaccharide contamination. ${ }^{94}$ Another reason for discrepancies in the results could be that the redox state of HMGB1 was not taken into account, which is important for the regulation of its functions. When the three cysteine residues (C23, C45, and C106) of HMGB1 are all in a reduced form, HMGB1 has chemotactic but no immunostimulatory properties, whereas HMGB1 has no chemotactic or immunostimulatory activities at all when all three cysteine residues are present in their oxidized form. ${ }^{95}$ Finally, when C106 is reduced, while C23 and C45 form an intermolecular disulfide bond, HMGB1 has immunostimulatory properties. ${ }^{92}$ In this intermediate state it will bind RAGE and the TLR2/4 receptors, leading to activation of the NF- $\kappa B$ pathway and subsequent secretion of proinflammatory cytokines. ${ }^{95}$ HMGB1 has also been shown to induce neutrophil extracellular trap formation in a TLR-4 dependent manner, a process where neutrophils release their nuclear DNA and associated proteins, including histones and myeloperoxidase into the extracellular space in response to DAMPs or pathogen-associated molecular patterns as a mechanism to capture and eradicate invading pathogens. ${ }^{96}$ Furthermore, HMGB1 also initiates intracellular histone 3 citrullination, a biochemical process that precedes chromatin decondensation. ${ }^{96}$ Citrullination and anticitrullinated protein antibody formation were found to be increased in COPD patients as compared with smoking controls. ${ }^{97}$

Some interesting studies have been performed in the past few years to investigate the role of HMGB1 in cigarette smokeinduced inflammation and COPD. Ferhani et al. $^{42}$ were the first to show elevated levels of HMGB1 in the BAL fluid of current smoking COPD patients as compared with smokers without COPD and nonsmokers. This upregulation was positively correlated with IL- $1 \beta$ levels and negatively correlated with the forced expiratory volume in $1 \mathrm{~s}\left(\mathrm{FEV}_{1} \%\right)$, the most important parameter for the severity of COPD. Later, it was shown that levels of HMGB1 are also higher in the sputum and serum of GOLD stage II-IV COPD patients as compared with healthy controls, and in ELF derived from the peripheral airways of COPD patients as compared with control smokers and nonsmokers. ${ }^{98,99}$ Altogether, these data suggest that HMGB1 levels in the extracellular space are increased in the COPD patients as compared with control individuals; however, it is at present unclear whether this is the result of necrotic cell death and subsequent release or active production and/or secretion. Moreover, it is currently unknown whether the release of HMGB1 is a direct consequence of smoking or whether it is related to the underlying inflammatory process in COPD, as HMGB1 levels are also increased in other unrelated chronic inflammatory diseases such as rheumatoid arthritis, systemic lupus erythematosus, scleroderma, and pulmonary fibrosis. ${ }^{81}$

In C57BL/6 mice, chronic cigarette smoke exposure (12 cigarettes per day, 60 days) was shown to induce an upregulation of HMGB1 protein expression in the lungs. ${ }^{100}$ In addition, the amount of HMGB1 was shown to increase in the serum of rats after subchronic cigarette smoke exposure (8 cigarettes per day, 4 weeks, 5 days per week) ${ }^{101}$ together indicating that cigarette smoke exposure alone is sufficient to induce increased extracellular HMGB1 levels. For future studies it is important to assess the role of cigarette smoke exposure in increased HMGB1 levels in the extracellular fluids of COPD patients. Furthermore, the redox state of extracellular HMGB1 is important to determine as different redox forms have different functions.

\section{Calreticulin}

Another well-known DAMP is CRT, ${ }^{102}$ a $46-\mathrm{kDa} \mathrm{Ca}^{2+}$. binding chaperone molecule that usually resides in the lumen of the ER. CRT is translocated from the lumen of the ER to the cell membrane during immunogenic apoptotic cell death. ${ }^{22,103,104}$ When CRT is expressed at the outer surface of the cell membrane, it serves as an "eat me" signal, being an essential recognition signal for phagocytosis. ${ }^{105}$ Exposure of CRT at the cell surface is a result of activation of ER stress pathways. ${ }^{103} \mathrm{ER}$ stress is an imbalance between ER protein folding load and capacity, and severe ER stress can result in the activation of proapoptotic signaling pathways. ${ }^{22}$ ER stress is induced in bronchial epithelial cells upon cigarette smoke exposure, ${ }^{106,107}$ and an exaggerated ER stress response was found in the lungs of COPD patients, potentially leading to the release of CRT. ${ }^{108,109}$

Very limited data are available on the role of CRT as a DAMP in the pathophysiology of COPD. It has been shown that CRT protein expression is significantly upregulated in CSE-treated human bronchial epithelial 16-HBE cells. ${ }^{110}$ Furthermore, the expression of CRT is upregulated in lung tissue lysates of smokers in comparison with nonsmokers and ex-smokers, which may serve as a regulatory mechanism to cope with misfolded proteins. ${ }^{110}$ Although CRT release has to our knowledge not been determined in COPD patients, increased protein expression may lead to increased levels upon immunogenic cell death and trigger inflammatory responses, contributing to the development of COPD. ${ }^{105}$

\section{DAMPS DERIVED FROM THE MITOCHONDRION Mitochondrial DNA}

Besides DAMPs derived from the cytoplasm, nucleus, or ER, recent data show that mitochondria are also an important source for DAMPs, the so-called mitochondrial DAMPs (mtDAMPs). ${ }^{11-113}$ This is a group of DAMPs that is currently 
known to exist of mtDNA, NFPs, ATP, and carbamoyl phosphate synthetase-1. ${ }^{111}$ The concept that mitochondria are a rich source of DAMPs derives from the endosymbiont hypothesis that states that mitochondria originate from protobacteria that have committed an endosymbiotic relationship with ancestral, phagocytic, unicellular anaerobes more than a billion years ago. ${ }^{114}$ Mitochondria still possess morphological and biochemical features of their prokaryotic ancestors, which may explain why many of their molecular patterns are recognized by PRRs. ${ }^{111}$ The mtDNA contains more unmethylated CpG motifs than genomic DNA. ${ }^{115}$ These unmethylated $\mathrm{CpG}$ motifs are responsible for the immunogenic properties of mtDNA, acting on TLR9. ${ }^{116}$ As for genomic DNA, mtDNA readily forms complexes with other DAMPs, including HMGB1 and LL37, which increases its immunostimulatory effects by facilitating uptake via RAGE after which it can bind to intracellular DNA sensors, including TLR9. ${ }^{73}$ The role of mtDNA in COPD remains to be elucidated, although it has been shown that mice develop rapid inflammation in the lungs when mitochondrial lysates are intravenously injected. ${ }^{117}$ This suggests a potential role of mtDAMPs in the pathophysiology of neutrophilic lung inflammation and COPD, although levels in extracellular lung fluids have not been studied.

\section{$\mathrm{N}$-formylated peptides}

The protein synthesis process of mitochondria resembles that of prokaryotes. Unlike eukaryotes, where protein synthesis is initiated by a nonformylated methionine residue, mitochondria and prokaryotes initiate protein synthesis by $\mathrm{N}$-formylmethionine, creating NFPs. Already in 1972, it has been shown that NFPs derived from bacteria are very potent chemoattractants for neutrophils, ${ }^{118,119}$ and in 1982 it was shown that NFPs derived from mitochondria also have this activity. ${ }^{120}$ NFPs are recognized by high-affinity formyl-peptide receptors (FPRs), which are G-coupled receptors expressed by numerous cells, including neutrophils, monocytes, dendritic cells, hepatocytes, and endothelial cells. ${ }^{121}$ There are three human FPR receptors: FPR1, FPR2, and FPR3. ${ }^{122}$ NFPs can activate neutrophils by binding FPR1, leading to the release of proinflammatory signals such as metalloproteinase- 8 and IL-8. ${ }^{123}$ NFPs released from necrotic cells have been shown to attract neutrophils to the site of injury, causing sterile inflammation. ${ }^{124}$

Although at present no studies have been performed investigating the role of NFPs as DAMPs in COPD patients, studies performed in mice indicate a critical role for NFP in cigarette smoke-induced lung inflammation and emphysema. Intratracheal application of fMLP, a synthetic FRP ligand, leads to increased inflammation, as shown by increased IL-13 staining, as well as emphysema and goblet cell metaplasia, characteristics of COPD. ${ }^{125}$ Importantly, it was recently shown that genetic ablation of the fprl gene, encoding for the mouse homolog of the FPR1 receptor, provides protection against cigarette smoke-induced emphysema in mice. ${ }^{126}$ In addition, a deficiency for $f p r 1$ in mice resulted in a strong decrease in lung infiltration of neutrophils and macrophages after exposure to cigarette smoke. ${ }^{126}$ This effect could also be achieved by using a FPR1 or FPR1/2 antagonist. ${ }^{126}$ Taken together, these data strongly suggest that NFP release upon cigarette smoke activates FRP1, leading to lung inflammation and emphysema. In line with the previous study, suggesting a role for NFPs in COPD, increased expression of FPR receptors on peripheral neutrophils has been observed in COPD patients and smoking controls, as compared with nonsmoking controls, reflecting a smoking-related, and thus not disease-related, effect. ${ }^{127}$

\section{Adenosine 5'-triphosphate}

ATP, a molecule that belongs to the purine family, is critical for transport of chemical energy within a cell, while it also has many signaling functions. ATP can be released into the extracellular space both actively and passively upon apoptotic and (secondary) necrotic cell death, where it can function as DAMP. ${ }^{128}$ ATP is produced in the mitochondrion but can be released from multiple subcellular compartments, including the cytoplasm, ER, and the mitochondrion. Extracellular ATP can activate purinergic receptors, which consists of two classes: the G-coupled protein P2Y class and the cation-permeable ligand gated ion channel P2X class of receptors. ${ }^{129}$ Activation of $\mathrm{P} 2 \mathrm{Y}$ receptors induces recruitment of neutrophils, macrophages, and dendritic cells to the side of injury. ${ }^{130,131}$ On the other hand, binding to P2X7 receptor leads to NLR-family pyrin domain containing 3 (NLRP3) inflammasome activation and subsequent release of the proinflammatory cytokine IL- $1 \beta$ from innate immune cells such as macrophages and dendritic cells. ${ }^{132}$ A role of extracellular ATP in COPD pathogenesis has been proposed, based on experimental animal models. ${ }^{131,133}$ $\mathrm{Balb} / \mathrm{c}$ mice exposed to cigarette smoke for 3 months showed increased ATP in the BAL fluid as compared with air-exposed control mice. ${ }^{133}$ Furthermore, CSE induces the release of ATP in human neutrophils. ${ }^{133}$ This increase in ATP may initiate release of IL- 8 and elastase by immune cells. Another indication that ATP has a role in the pathogenesis of COPD was the observation that ATP levels are increased in the BAL fluid of COPD patients. ${ }^{131}$ Moreover, higher ATP levels have been observed in current and ex-smoking COPD patients as compared with both smoking and nonsmoking controls, whereas levels were also increased in smokers compared with nonsmokers. ${ }^{131}$ Importantly, this increase in ATP was negatively correlated with the $\mathrm{FEV}_{1} \%$. Furthermore, acute smoke exposure ( 8 cigarettes in $4 \mathrm{~h}$ ) has been shown to induce an immediate increase of ATP in the BAL fluid of healthy controls, indicating a direct effect of smoking on BAL ATP levels. As ATP levels in BAL of COPD patients were even higher, there may be an additional disease-related effect. ${ }^{131}$ The same study also showed that in current smoking and ex-smoking COPD patients, the expression of $\mathrm{P} 2 \mathrm{Y} 2$ and $\mathrm{P} 2 \mathrm{X} 7$ receptors on blood neutrophils and macrophages is higher than in smoking and nonsmoking controls. The role of purinergic receptors in smoke-induced lung inflammation was supported by in vivo mice studies showing an upregulation of $\mathrm{P} 2 \mathrm{X} 7$ and $\mathrm{P} 2 \mathrm{Y} 2$ receptors on neutrophils, macrophages, and lung tissue in mice after short-term smoke exposure. ${ }^{134,135}$ When either one of these receptors was knocked out, less inflammation and 
Table 1 DAMPs and their levels in COPD patients

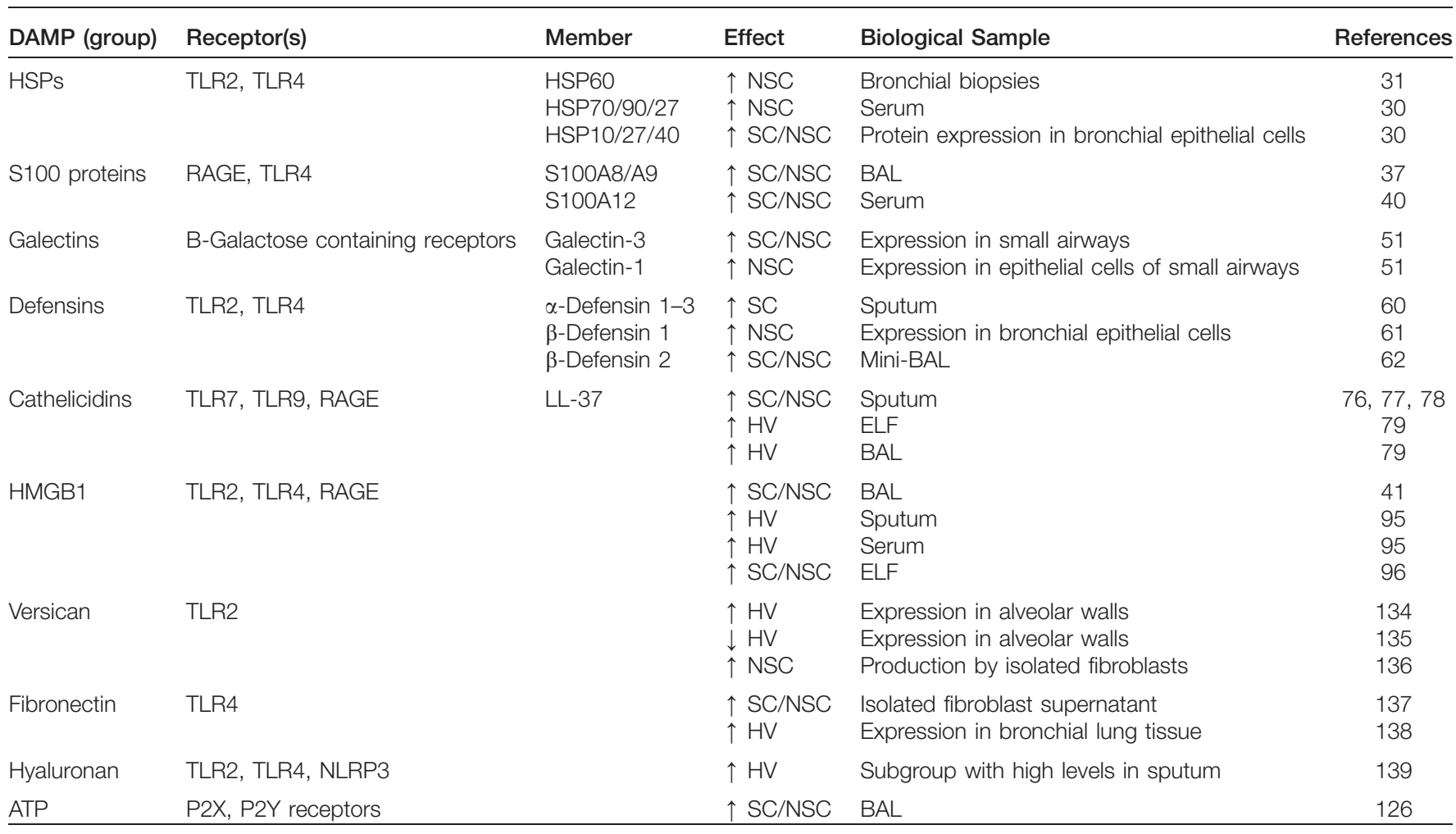

ATP, adenosine 5'-triphosphate; BAL, bronchoalveolar lavage; COPD, chronic obstructive pulmonary disease; DAMP, damage-associated molecular pattern; ELF, epithelial lining fluid; HMGB1, high-mobility group box-1; HSP, heat shock protein; HV, healthy volunteers with unknown smoking status; NLRP3, NLR-family pyrin domain containing 3; NSC, nonsmoking controls; RAGE, receptor for advanced glycation end-products; SC, smoking controls; TLR, Toll-like receptor.

Effect in (ex)-smoking COPD patients as compared with NSCs, SCs, and HVs.

emphysema was observed in the lungs of mice after smoke exposure. ${ }^{134,135}$ Furthermore, P2Y2R knockout mice showed attenuated inflammation in the lungs after acute cigarette smoke exposure compared with $\mathrm{C} 57 \mathrm{Bl} / 6 \mathrm{~J}$ wild-type mice. ${ }^{135}$ Together, these studies suggest that there may be a role for ATP in the pathogenesis of COPD, both with respect to neutrophilic airway inflammation and emphysema.

Besides the mtDAMPs discussed above, additional mtDAMPs may exist, e.g., carbamoyl phosphate synthetase1 (ref. 111) ${ }^{111}$ and cardiolipin. ${ }^{136}$ To date, there is little evidence indicating a role in COPD, although it has previously been shown that BAL levels of cardiolipin are significantly higher in COPD patients than in nonsmoking controls. ${ }^{137}$ Further research needs to clarify whether all or specific mtDAMPs are increased in the lungs of COPD patients and whether they play a role in disease pathogenesis.

\section{DAMPs DERIVED FROM THE ECM}

Recently, the awareness has arisen that not only intracellular molecules, but also molecules from the ECM can activate the immune system in response to danger when released from the ECM upon cleavage by metalloproteases. ${ }^{28,138}$ As this review focuses on cellular-derived DAMPs, we will not extensively discuss ECM DAMPs, although there is some evidence that ECM DAMPs are involved in COPD pathogenesis. Increased protein expression of versican ${ }^{139-141}$ and fibronectin ${ }^{142,143}$ has been observed in the lungs of COPD patients, whereas for other ECM DAMPs, e.g., low-molecular-weight hyaluronan, ${ }^{144,145}$ higher levels of proinflammatory breakdown products have been found in the BAL fluid of COPD patients (see Table 1). These DAMPs may play a role in the pathogenesis of COPD, as most of these DAMPs can activate TLR2 and TLR4 downstream NF- $\kappa B$ pathways, thereby inducing or maintaining proinflammatory activation of the innate immune system. ${ }^{8}$

\section{CONCLUDING REMARKS}

In this review, various relevant DAMPs and their potential roles in COPD pathogenesis are discussed. Since the proposal of the danger hypothesis by Matzinger ${ }^{11}$ in 1994, many danger signals have been discovered, several of which may have a pathogenic role in COPD. Increasing numbers of publications have studied the presence of DAMPs in extracellular lung fluids, including BAL, ELF, and sputum. Higher levels of HMGB1, S100A8/A9, low-molecular-weight hyaluronan, ATP, and $\beta$-defensin have been observed in the BAL fluid of COPD patients as compared with controls, providing possible biomarkers for the detection of COPD at early disease state (see Table 1). To date, no studies have been performed to assess a larger set of DAMPs in order to identify the DAMP signature in COPD patients. This could be of interest considering that not all DAMPs are equally increased in lung tissue and/or released in the extracellular space of 
COPD patients. Furthermore, it is currently unknown what the contribution of individual DAMPs is in the progression of COPD, and whether all DAMPs have similar effects, whether specific DAMPs are more pathogenic than others, or whether simultaneous release of multiple DAMPs is required to drive innate and adaptive immune responses in COPD. The latter can be examined by intervention studies both in vitro and in preclinical in vivo models. After identifying the DAMP signature in the lungs of COPD patients, the next step will be to interfere with the immune stimulatory effect of DAMPs and to assess whether this will attenuate chronic lung inflammation. The immunologic effects of DAMPs can be inhibited by the use of neutralizing peptides or antibodies to specific DAMPs, preventing their binding to PRRs. Another possibility is to inhibit the release of DAMPs by inhibiting immunogenic cell death. This can be done by: promoting damaged cells to go into nonimmunogenic apoptosis instead of necrosis or necroptosis, as apoptosis does not lead to release of immunogenic DAMPs, ${ }^{20,102}$ by inhibiting necroptosis, ${ }^{146}$ or by initiating more efficient phagocytosis. ${ }^{15}$ Furthermore, DAMP-mediated inflammation can be reduced by inhibition of specific PRRs, thereby disabling specific DAMPs to exert their functions. It has already been shown that TLR4, fpr 1 , and $P 2 Y 2 R$ knockout mice have attenuated inflammation in the lungs after acute cigarette smoke exposure. ${ }^{126,135,147}$ However, an even stronger reduction in inflammation was observed after acute cigarette smoke exposure when multiple PRRs were inhibited simultaneously by knocking out $M y D 88$, a crucial signaling adaptor molecule for most TLRs. ${ }^{147}$ Nevertheless, this decrease in inflammation was only seen after acute and not after prolonged cigarette smoke exposure, when the adaptive immune reaction is thought to crucially contribute to COPD pathogenesis. ${ }^{148}$

To the best of our knowledge, targeting DAMPs or their signaling pathways in COPD patients have not yet been performed. More research into the critical forms of cell death and DAMP signatures in COPD patients as well as the critical downstream PRRs may open new avenues for therapeutic intervention in this chronic disease for which current medication is lacking.

In conclusion, multiple studies have shown that the levels of specific DAMPs are higher in the BAL fluid of COPD patients as compared with healthy individuals, and there is suggestive evidence for a role in the initiation of chronic airway inflammation in COPD. Thus, DAMPs may provide potential therapeutic targets to reduce the chronic inflammation in the lungs of COPD patients as well as potential biomarkers for the detection of COPD at an early disease state.

\section{ACKNOWLEDGMENTS}

This study is supported by the Dutch Lung Foundation (project: 3.2.11.025) and was funded by the Netherlands Asthma Foundation (project 3.2.11.025).

\section{DISCLOSURE}

The authors declared no conflict of interest.

c 2014 Society for Mucosal Immunology

\section{REFERENCES}

1. Halbert, R.J. et al. Global burden of COPD: systematic review and metaanalysis. Eur. Respir. J. 28, 523-532 (2006).

2. World Health Organisation. WHO. World Health Statistics http:// www.who.int/whois/whostat/EN_WHS08_Full.pdf2008).

3. Barnes, P.J., Shapiro, S.D. \& Pauwels, R.A. Chronic obstructive pulmonary disease: molecular and cellular mechanisms. Eur. Respir. J. 22, 672-688 (2003)

4. Barnes, P.J. Immunology of asthma and chronic obstructive pulmonary disease. Nat. Rev. Immunol. 8, 183-192 (2008).

5. Brusselle, G.G., Joos, G.F. \& Bracke, K.R. New insights into the immunology of chronic obstructive pulmonary disease. Lancet $\mathbf{3 7 8}$, 1015-1026 (2011).

6. Bruce, N., Perez-Padilla, R. \& Albalak, R. Indoor air pollution in developing countries: a major environmental and public health challenge. Bull. World Health Organ. 78, 1078-1092 (2000).

7. O'Donnell, R., Breen, D., Wilson, S. \& Djukanovic, R. Inflammatory cells in the airways in COPD. Thorax 61, 448-454 (2006).

8. Cosio, M.G., Saetta, M. \& Agusti, A. Immunologic aspects of chronic obstructive pulmonary disease. N. Engl. J. Med. 360, 2445-2454 (2009).

9. Gruffydd-Jones, K. GOLD guidelines 2011: what are the implications for primary care? Prim. Care Respir. J. 21, 437-441 (2012).

10. Curtis, J.L., Freeman, C.M. \& Hogg, J.C. The immunopathogenesis of chronic obstructive pulmonary disease: insights from recent research. Proc. Am. Thorac. Soc. 4, 512-521 (2007).

11. Matzinger, P. Tolerance, danger, and the extended family. Annu. Rev. Immunol. 12, 991-1045 (1994).

12. Messner, B. et al. Apoptosis and necrosis: two different outcomes of cigarette smoke condensate-induced endothelial cell death. Cell Death Dis. 3, e424 (2012).

13. Kaczmarek, A., Vandenabeele, P. \& Krysko, D.V. Necroptosis: the release of damage-associated molecular patterns and its physiological relevance. Immunity 38, 209-223 (2013).

14. Kono, H. \& Rock, K.L. How dying cells alert the immune system to danger. Nat. Rev. Immunol. 8, 279-289 (2008).

15. Krysko, O., Vandenabeele, P., Krysko, D.V. \& Bachert, C. Impairment of phagocytosis of apoptotic cells and its role in chronic airway diseases. Apoptosis 15, 1137-1146 (2010).

16. Gallo, P.M. \& Gallucci, S. The dendritic cell response to classic, emerging, and homeostatic danger signals. Implications for autoimmunity. Front. Immunol. 4, 138 (2013).

17. Kasahara, Y. et al. Endothelial cell death and decreased expression of vascular endothelial growth factor and vascular endothelial growth factor receptor 2 in emphysema. Am. J. Respir. Crit. Care Med. 163, 737-744 (2001).

18. Tuder, R.M. \& Petrache, I. Pathogenesis of chronic obstructive pulmonary disease. J. Clin. Invest. 122, 2749-2755 (2012).

19. Van der Toorn, M. et al. Cigarette smoke-induced blockade of the mitochondrial respiratory chain switches lung epithelial cell apoptosis into necrosis. Am. J. Physiol. Lung Cell. Mol. Physiol. 292, L1211-L1218 (2007).

20. Martin, S.J., Henry, C.M. \& Cullen, S.P. A perspective on mammalian caspases as positive and negative regulators of inflammation. Mol. Cell 46, 387-397 (2012)

21. Hirsiger, S., Simmen, H.-P., Werner, C.M.L., Wanner, G.a. \& Rittirsch, D. Danger signals activating the immune response after trauma. Mediators Inflamm. 2012, 315941 (2012).

22. Krysko, D.V. et al. Immunogenic cell death and DAMPs in cancer therapy. Nat. Rev. Cancer 12, 860-875 (2012)

23. Vanden Berghe, T. et al. Necrosis is associated with IL-6 production but apoptosis is not. Cell. Signal. 18, 328-335 (2006).

24. Chen, G.Y. \& Nuñez, G. Sterile inflammation: sensing and reacting to damage. Nat. Rev. Immunol. 10, 826-837 (2010).

25. Joly, A.-L., Wettstein, G., Mignot, G., Ghiringhelli, F. \& Garrido, C. Dual role of heat shock proteins as regulators of apoptosis and innate immunity. J. Innate Immun. 2, 238-247 (2010).

26. Multhoff, G. Heat shock protein 70 (Hsp70): membrane location, export and immunological relevance. Methods 43, 229-237 (2007).

27. Asea, A., Kabingu, E., Stevenson, M.A. \& Calderwood, S.K. HSP70 peptidembearing and peptide-negative preparations act as chaperokines. Cell Stress Chaperones 5, 425-431 (2000). 
28. Tolle, L.B. \& Standiford, T.J. Danger associated molecular patterns (DAMPs) in acute lung injury. J. Pathol. 229, 1-34 (2013).

29. Asea, A. et al. Novel signal transduction pathway utilized by extracellular HSP70: role of toll-like receptor (TLR) 2 and TLR4. J. Biol. Chem. 277, 15028-15034 (2002).

30. Pinot, F., el Yaagoubi, A., Christie, P., Dinh-Xuan, A.T. \& Polla, B.S. Induction of stress proteins by tobacco smoke in human monocytes: modulation by antioxidants. Cell Stress Chaperones 2, 156-161 (1997).

31. Hacker, S. et al. Elevated HSP27, HSP70 and HSP90 alpha in chronic obstructive pulmonary disease: markers for immune activation and tissue destruction. Clin. Lab. 55, 31-40 (2009).

32. Cappello, F. et al. Convergent sets of data from in vivo and in vitro methods point to an active role of hsp60 in chronic obstructive pulmonary disease pathogenesis. PLoS One 6, e28200 (2011).

33. Kreutmayer, S.B. et al. Dynamics of heat shock protein 60 in endothelial cells exposed to cigarette smoke extract. J. Mol. Cell. Cardiol. 51, 777-780 (2011).

34. Heizmann, C.W., Ackermann, G.E. \& Galichet, A. Pathologies involving the S100 proteins and RAGE. Subcell. Biochem. 45, 93-138 (2007).

35. Edgeworth, J., Gorman, M., Bennett, R., Freemont, P. \& Hogg, N. Identification of $\mathrm{p} 8,14$ as a highly abundant heterodimeric calcium binding protein complex of myeloid cells. J. Biol. Chem. 266, 7706-7713 (1991).

36. Rammes, A. et al. Myeloid-related protein (MRP) 8 and MRP14, calciumbinding proteins of the $\mathrm{S} 100$ family, are secreted by activated monocytes via a novel, tubulin-dependent pathway. J. Biol. Chem. 272, 9496-9502 (1997).

37. Srikrishna, G. S100A8 and S100A9: new insights into their roles in malignancy. J. Innate Immun. 4, 31-40 (2012).

38. Merkel, D., Rist, W., Seither, P., Weith, A. \& Lenter, M.C. Proteomic study of human bronchoalveolar lavage fluids from smokers with chronic obstructive pulmonary disease by combining surface-enhanced laser desorption/ionization-mass spectrometry profiling with mass spectrometric protein identification. Proteomics 5, 2972-2980 (2005).

39. Lorenz, E. et al. Different expression ratio of S100A8/A9 and S100A12 in acute and chronic lung diseases. Respir. Med. 102, 567-573 (2008).

40. Miniati, M. et al. Soluble receptor for advanced glycation end products in COPD: relationship with emphysema and chronic cor pulmonale: a casecontrol study. Respir. Res. 12, 37 (2011).

41. Cockayne, D.a. et al. Systemic biomarkers of neutrophilic inflammation, tissue injury and repair in COPD patients with differing levels of disease severity. PLoS One 7, e38629 (2012).

42. Ferhani, N. et al. Expression of high-mobility group box 1 and of receptor for advanced glycation end products in chronic obstructive pulmonary disease. Am. J. Respir. Crit. Care Med. 181, 917-927 (2010).

43. Smith, D.J. et al. Reduced soluble receptor for advanced glycation endproducts in COPD. Eur. Respir. J. 37, 516-522 (2011).

44. Sukkar, M.B. et al. Soluble RAGE is deficient in neutrophilic asthma and COPD. Eur. Respir. J. 39, 721-729 (2012).

45. Sukkar, M.B. et al. RAGE: a new frontier in chronic airways disease. Br. J. Pharmacol., 1-37 (2012).

46. Hancock, D.B. et al. Meta-analyses of genome-wide association studies identify multiple loci associated with pulmonary function. Nat. Genet. $\mathbf{4 2}$, 45-52 (2010)

47. Repapi, E. et al. Genome-wide association study identifies five loci associated with lung function. Nat. Genet. 42, 36-44 (2010).

48. Liu, F.-T., Yang, R.-Y. \& Hsu, D.K. Galectins in acute and chronic inflammation. Ann. NY Acad. Sci. 1253, 80-91 (2012).

49. Sato, S., St-Pierre, C., Bhaumik, P. \& Nieminen, J. Galectins in innate immunity: dual functions of host soluble beta-galactoside-binding lectins as damage-associated molecular patterns (DAMPs) and as receptors for pathogen-associated molecular patterns (PAMPs). Immunol. Rev. 230, 172-187 (2009).

50. Liu, F.-T. \& Rabinovich, G.a. Galectins: regulators of acute and chronic inflammation. Ann. NY Acad Sci. 1183, 158-182 (2010).

51. Bhaumik, P., St-Pierre, G., Milot, V., St-Pierre, C. \& Sato, S. Galectin-3 facilitates neutrophil recruitment as an innate immune response to a parasitic protozoa cutaneous infection. J. Immunol. 190, 630-640 (2012).

52. Pilette, C. et al. Increased galectin-3 expression and intra-epithelial neutrophils in small airways in severe COPD. Eur. Respir. J. 29, 914-922 (2007).
53. Vega-Carrascal, I. et al. Dysregulation of TIM-3-galectin-9 pathway in the cystic fibrosis airways. J. Immunol. 186, 2897-2909 (2011).

54. Cederlund, A., Gudmundsson, G.H. \& Agerberth, B. Antimicrobial peptides important in innate immunity. FEBS J. 278, 3942-3951 (2011).

55. Ganz, T. Defensins: antimicrobial peptides of innate immunity. Nat. Rev. Immunol. 3, 710-720 (2003)

56. Rosin, D.L. \& Okusa, M.D. Dangers within: DAMP responses to damage and cell death in kidney disease. J. Am. Soc. Nephrol. 22, 416-425 (2011).

57. Biragyn, A. et al. Murine beta-defensin 2 promotes TLR-4/MyD88mediated and NF-kappaB-dependent atypical death of APCs via activation of TNFR2. J. Leukoc. Biol. 83, 998-1008 (2008).

58. Chaly, Y.V. et al. Neutrophil alpha-defensin human neutrophil peptide modulates cytokine production in human monocytes and adhesion molecule expression in endothelial cells. Eur. Cytokine Netw. 11, 257-266 (2000).

59. Yang, D., Chen, Q., Chertov, O. \& Oppenheim, J.J. Human neutrophil defensins selectively chemoattract naive T and immature dendritic cells. J. Leukoc. Biol. 68, 9-14 (2000).

60. Van Wetering, S., Mannesse-Lazeroms, S.P.G., van Sterkenburg, M.A.J.A. \& Hiemstra, P.S. Neutrophil defensins stimulate the release of cytokines by airway epithelial cells: modulation by dexamethasone. Inflamm. Res. 51, 8-15 (2002).

61. Paone, G. et al. Human neutrophil peptides sputum levels in symptomatic smokers and COPD patients. Eur. Rev. Med. Pharmacol. Sci. 15, 556-562 (2011).

62. Andresen, E., Günther, G., Bullwinkel, J., Lange, C. \& Heine, H. Increased expression of beta-defensin 1 (DEFB1) in chronic obstructive pulmonary disease. PLoS One 6, e21898 (2011).

63. Pace, E. et al. TLR4 upregulation underpins airway neutrophilia in smokers with chronic obstructive pulmonary disease and acute respiratory failure. Hum. Immunol. 72, 54-62 (2011).

64. Tsoumakidou, M., Bouloukaki, I., Thimaki, K., Tzanakis, N. \& Siafakas, N.M. Innate immunity proteins in chronic obstructive pulmonary disease and idiopathic pulmonary fibrosis. Exp. Lung Res. 36, 373-380 (2010).

65. Chen, L. et al. Cigarette smoke enhances $\{$ beta\}-defensin 2 expression in rat airways via nuclear factor-\{kappa\}B activation. Eur. Respir. J. 36, 638-645 (2010).

66. Garcha, D.S. et al. Changes in prevalence and load of airway bacteria using quantitative PCR in stable and exacerbated COPD. Thorax 67, 1075-1080 (2012).

67. Almansa, R. et al. Viral infection is associated with an increased proinflammatory response in chronic obstructive pulmonary disease. Viral Immunol. 25, 249-253 (2012).

68. Zanetti, M., Gennaro, R. \& Romeo, D. Cathelicidins: a novel protein family with a common proregion and a variable C-terminal antimicrobial domain. FEBS Lett. 374, 1-5 (1995).

69. Cowland, J.B., Johnsen, A.H. \& Borregaard, N. hCAP-18, a cathelin/probactenecin-like protein of human neutrophil specific granules. FEBS Lett. 368, 173-176 (1995).

70. Bals, R. et al. The peptide antibiotic LL-37/hCAP-18 is expressed in epithelia of the human lung where it has broad antimicrobial activity at the airway surface. Proc. Natl. Acad. Sci. USA 95, 9541-9546 (1998).

71. Agerberth, B. et al. Antibacterial components in bronchoalveolar lavage fluid from healthy individuals and sarcoidosis patients. Am. J. Respir. Crit. Care Med. 160, 283-290 (1999).

72. Zaiou, M. \& Gallo, R.L. Cathelicidins, essential gene-encoded mammalian antibiotics. J. Mol. Med. 80, 549-561 (2002).

73. Takeuchi, O. \& Akira, S. Pattern recognition receptors and inflammation. Cell 140, 805-820 (2010).

74. Zhang, J. et al. Novel sulfated polysaccharides disrupt cathelicidins, inhibit RAGE and reduce cutaneous inflammation in a mouse model of rosacea. PLoS One 6, e16658 (2011).

75. Tjabringa, G.S., Ninaber, D.K., Drijfhout, J.W., Rabe, K.F. \& Hiemstra, P.S. Human cathelicidin LL-37 is a chemoattractant for eosinophils and neutrophils that acts via formyl-peptide receptors. Int. Arch. Allergy Immunol. 140, 103-112 (2006).

76. Shaykhiev, R. et al. Human endogenous antibiotic LL-37 stimulates airway epithelial cell proliferation and wound closure. Am. J. Physiol. 289, L842-L848 (2005). 
77. Jiang, Y.-Y. et al. The effect of human antibacterial peptide LL-37 in the pathogenesis of chronic obstructive pulmonary disease. Respir. Med. 106, 1680-1689 (2012).

78. Parameswaran, G.I., Sethi, S. \& Murphy, T.F. Effects of bacterial infection on airway antimicrobial peptides and proteins in COPD. Chest 140, 611-617 (2011).

79. Xiao, W., Hsu, Y.-P., Ishizaka, A., Kirikae, T. \& Moss, R.B. Sputum cathelicidin, urokinase plasminogen activation system components, and cytokines discriminate cystic fibrosis, COPD, and asthma inflammation. Chest 128, 2316-2326 (2005).

80. Golec, M. et al. Cathelicidin LL-37 in bronchoalveolar lavage and epithelial lining fluids from COPD patients and healthy individuals. J. Biol. Regul. Homeost. Agents 26, 617-625 (2012).

81. Sims, G.P., Rowe, D.C., Rietdijk, S.T., Herbst, R. \& Coyle, A.J. HMGB1 and RAGE in inflammation and cancer. Annu. Rev. Immunol. 28, 367-388 (2010).

82. Andersson, U. et al. High mobility group 1 protein (HMG-1) stimulates proinflammatory cytokine synthesis in human monocytes. J. Exp. Med. 192, 565-570 (2000).

83. Bell, C.W., Jiang, W., Reich, C.F. \& Pisetsky, D.S. The extracellular release of HMGB1 during apoptotic cell death. Am. J. Physiol. 291, C1318-C1325 (2006).

84. Gardella, S. et al. The nuclear protein HMGB1 is secreted by monocytes via a non-classical, vesicle-mediated secretory pathway. EMBO Rep. 3, 995-1001 (2002).

85. Kokkola, R. et al. RAGE is the major receptor for the proinflammatory activity of HMGB1 in rodent macrophages. Scand. J. Immunol. 61, 1-9 (2005).

86. Park, J.S. et al. Involvement of toll-like receptors 2 and 4 in cellular activation by high mobility group box 1 protein. J. Biol. Chem. 279, 7370-7377 (2004).

87. Lippai, D. et al. Alcohol-induced IL-1 $\beta$ in the brain is mediated by NLRP3/ ASC inflammasome activation that amplifies neuroinflammation. J. Leukoc. Biol. 94, 171-182 (2013).

88. Bianchi, M.E. HMGB1 loves company. J. Leukoc. Biol. 86, 573-576 (2009).

89. Hreggvidsdottir, H.S. et al. The alarmin HMGB1 acts in synergy with endogenous and exogenous danger signals to promote inflammation. J. Leukoc. Biol. 86, 655-662 (2009).

90. Bianchi, M.E. DAMPs, PAMPs and alarmins: all we need to know about danger. J. Leukoc. Biol. 81, 1-5 (2007).

91. Dumitriu, I.E., Baruah, P., Bianchi, M.E., Manfredi, A.A. \& Rovere-Querini, P. Requirement of HMGB1 and RAGE for the maturation of human plasmacytoid dendritic cells. Eur. J. Immunol. 35, 2184-2190 (2005).

92. Yanai, H., Ban, T. \& Taniguchi, T. High-mobility group box family of proteins: ligand and sensor for innate immunity. Trends Immunol. 33, 633-640 (2012).

93. Rouhiainen, A., Tumova, S., Valmu, L., Kalkkinen, N. \& Rauvala, H. Pivotal advance: analysis of proinflammatory activity of highly purified eukaryotic recombinant HMGB1 (amphoterin). J. Leukoc. Biol. 81, 49-58 (2007).

94. Pisetsky, D. Cell death in the pathogenesis of immune-mediated diseases: the role of HMGB1 and DAMP-PAMP complexes. Swiss Med. Wkly. 141, w13256 (2011).

95. Venereau, E. et al. Mutually exclusive redox forms of HMGB1 promote cell recruitment or proinflammatory cytokine release. J. Exp. Med. 209, 1519-1528 (2012)

96. Tadie, J.-M. et al. HMGB1 promotes neutrophil extracellular trap formation through interactions with Toll-like receptor 4. Am. J. Physiol. 304, L342-L349 (2013).

97. Wood, A.M., de Pablo, P., Buckley, C.D., Ahmad, A. \& Stockley, R.A. Smoke exposure as a determinant of autoantibody titre in $\alpha_{1}$-antitrypsin deficiency and COPD. Eur. Respir. J. 37, 32-38 (2011).

98. Hou, C. et al. High mobility group protein B1 (HMGB1) in asthma: comparison of patients with chronic obstructive pulmonary disease and healthy controls. Mol. Med. 17, 807-815 (2011).

99. Kanazawa, $\mathrm{H}$. et al. Validity of HMGB1 measurement in epithelial lining fluid in patients with COPD. Eur. J. Clin. Invest. 42, 419-426 (2011).

100. Bezerra, F.S. et al. Long-term exposure to cigarette smoke impairs lung function and increases HMGB-1 expression in mice. Respir. Physiol. Neurobiol. 177, 120-126 (2011).
101. Saiwichai, T. et al. Green tea extract supplement inhibition of HMGB1 release in rats exposed to cigarette smoke. Southeast Asian J. Trop. Med. Public Health 41, 250-258 (2010).

102. Garg, A.D. et al. Immunogenic cell death, DAMPs and anticancer therapeutics: an emerging amalgamation. Biochim. Biophys. Acta 1805, 53-71 (2010).

103. Garg, A.D. et al. A novel pathway combining calreticulin exposure and ATP secretion in immunogenic cancer cell death. EMBO J. 31 , 1062-1079 (2012).

104. Kepp, O. et al. Immunogenic cell death modalities and their impact on cancer treatment. Apoptosis 14, 364-375 (2009).

105. Gardai, S.J. et al. Cell-surface calreticulin initiates clearance of viable or apoptotic cells through trans-activation of LRP on the phagocyte. Cell 123, 321-334 (2005).

106. Somborac-Bacura, A. et al. Cigarette smoke induces endoplasmic reticulum stress response and proteasomal dysfunction in human alveolar epithelial cells. Exp. Physiol. 98, 316-325 (2013).

107. Jorgensen, E. et al. Cigarette smoke induces endoplasmic reticulum stress and the unfolded protein response in normal and malignant human lung cells. BMC Cancer 8, 229 (2008).

108. Malhotra, D. et al. Heightened endoplasmic reticulum stress in the lungs of patients with chronic obstructive pulmonary disease: the role of Nrf2-regulated proteasomal activity. Am. J. Respir. Crit. Care Med. 180, 1196-1207 (2009).

109. Ribeiro, C.M.P. \& O'Neal, W.K. Endoplasmic reticulum stress in chronic obstructive lung diseases. Curr. Mol. Med. 12, 872-882 (2012).

110. Kelsen, S.G. et al. Cigarette smoke induces an unfolded protein response in the human lung: a proteomic approach. Am. J. Respir. Cell Mol. Biol. 38, 541-550 (2008).

111. Krysko, D.V. et al. Emerging role of damage-associated molecular patterns derived from mitochondria in inflammation. Trends Immunol. 32, 157-164 (2011).

112. Schwacha, M.G., Rani, M., Zhang, Q., Nunez-Cantu, O. \& Cap, A.P. Mitochondrial damage-associated molecular patterns activate $\gamma \delta$ T-cells. Innate Immun. (2013; e-pub ahead of print).

113. Sun, S. et al. Mitochondrial DAMPs increase endothelial permeability through neutrophil dependent and independent pathways. PLoS One 8, e59989 (2013).

114. Gray, M.W. Mitochondrial evolution. Cold Spring Harb. Perspect. Biol. 4, a011403 (2012).

115. Collins, L.V. et al. Endogenously oxidized mitochondrial DNA induces in vivo and in vitro inflammatory responses. J. Leukoc. Biol. 75, 995-1000 (2004).

116. Krieg, A.M. The role of CpG motifs in innate immunity. Curr. Opin. Immunol. 12, 35-43 (2000).

117. Zhang, Q. et al. Circulating mitochondrial DAMPs cause inflammatory responses to injury. Nature 464, 104-107 (2010).

118. Schiffmann, E. et al. The isolation and partial characterization of neutrophil chemotactic factors from Escherichia coli. J. Immunol. 114, 1831-1837 (1975).

119. Schiffmann, E., Corcoran, B.A. \& Wahl, S.M. N-formylmethionyl peptides as chemoattractants for leucocytes. Proc. Natl. Acad. Sci. USA 72, 1059-1062 (1975).

120. Carp, H. Mitochondrial N-formylmethionyl proteins as chemoattractants for neutrophils. J. Exp. Med. 155, 264-275 (1982).

121. Migeotte, I., Communi, D. \& Parmentier, M. Formyl peptide receptors: a promiscuous subfamily of $G$ protein-coupled receptors controlling immune responses. Cytokine Growth Factor Rev. 17, 501-519 (2006).

122. Boulay, F., Tardif, M., Brouchon, L. \& Vignais, P. The human N-formylpeptide receptor. Characterization of two cDNA isolates and evidence for a new subfamily of G-protein-coupled receptors. Biochemistry 29 , 11123-11133 (1990).

123. Raoof, M., Zhang, Q., Itagaki, K. \& Hauser, C.J. Mitochondrial peptides are potent immune activators that activate human neutrophils via FPR-1. J. Trauma 68, 1328-1332. discussion 1332-4 (2010).

124. McDonald, B. et al. Intravascular danger signals guide neutrophils to sites of sterile inflammation. Science 330, 362-366 (2010).

125. Atzori, L. et al. Absence of proteinase-activated receptor-1 signaling in mice confers protection from fMLP-induced goblet cell metaplasia. Am. J. Respir. Cell Mol. Biol. 41, 680-687 (2009). 
126. Cardini, S. et al. Genetic ablation of the fpr1 gene confers protection from smoking-induced lung emphysema in mice. Am. J. Respir. Cell Mol. Biol. 47, 332-339 (2012).

127. Matheson, M., Rynell, A.-C., McClean, M. \& Berend, N. Cigarette smoking increases neutrophil formyl methionyl leucyl phenylalanine receptor numbers. Chest 123, 1642-1646 (2003).

128. Ghiringhelli, F. et al. Activation of the NLRP3 inflammasome in dendritic cells induces IL-1beta-dependent adaptive immunity against tumors. Nat. Med. 15, 1170-1178 (2009).

129. Mortaz, E., Folkerts, G., Nijkamp, F.P. \& Henricks, P.a.J. ATP and the pathogenesis of COPD. Eur. J. Pharmacol. 638, 1-4 (2010).

130. Chen, Y. et al. ATP release guides neutrophil chemotaxis via P2Y2 and A3 receptors. Science 314, 1792-1795 (2006).

131. Lommatzsch, M. et al. Extracellular adenosine triphosphate and chronic obstructive pulmonary disease. Am. J. Respir. Crit. Care Med. 181, 928-934 (2010).

132. Ferrari, D. et al. Extracellular ATP triggers IL-1 beta release by activating the purinergic P2Z receptor of human macrophages. J. Immunol. 159, 1451-1458 (1997).

133. Mortaz, E. et al. ATP in the pathogenesis of lung emphysema. Eur. J. Pharmacol. 619, 92-96 (2009).

134. Lucattelli, M. et al. P2 $\times 7$ receptor signaling in the pathogenesis of smoke-induced lung inflammation and emphysema. Am. J. Respir. Cell Mol. Biol. 44, 423-429 (2011).

135. Cicko, S. et al. Purinergic receptor inhibition prevents the development of smoke-induced lung injury and emphysema. J. Immunol. 185, 688-697 (2010).

136. Sorice, M. et al. Cardiolipin and its metabolites move from mitochondria to other cellular membranes during death receptor-mediated apoptosis. Cell Death Differ. 11, 1133-1145 (2004).

137. Lusuardi, M. et al. Role of surfactant in chronic obstructive pulmonary disease: therapeutic implications. Respiration 59 (Suppl 1), 28-32 (1992).
138. Van Crombruggen, K., Jacob, F., Zhang, N. \& Bachert, C. Damageassociated molecular patterns and their receptors in upper airway pathologies. Cell. Mol. Life Sci. (2013; e-pub ahead of print).

139. Hallgren, O. et al. Altered fibroblast proteoglycan production in COPD. Respir. Res. 11, 55 (2010).

140. Merrilees, M.J. et al. Changes in elastin, elastin binding protein and versican in alveoli in chronic obstructive pulmonary disease. Respir. Res. 9, 41 (2008).

141. Annoni, R. et al. Extracellular matrix composition in chronic obstructive pulmonary disease. Eur. Respir. J. 40, 1362-1373 (2012).

142. Krimmer, D.I., Burgess, J.K., Wooi, T.K., Black, J.L. \& Oliver, B.G.G. Matrix proteins from smoke-exposed fibroblasts are pro-proliferative. Am. J. Respir. Cell Mol. Biol. 46, 34-39 (2012).

143. Kranenburg, A.R. et al. Enhanced bronchial expression of extracellular matrix proteins in chronic obstructive pulmonary disease. Am. J. Clin. Pathol. 126, 725-735 (2006).

144. Bracke, K.R. et al. Enhanced deposition of low-molecular-weight hyaluronan in lungs of cigarette smoke-exposed mice. Am. J. Respir. Cell Mol. Biol. 42, 753-761 (2010).

145. Dentener, M.A., Vernooy, J.H.J., Hendriks, S. \& Wouters, E.F.M. Enhanced levels of hyaluronan in lungs of patients with COPD: relationship with lung function and local inflammation. Thorax 60 , 114-119 (2005).

146. Cho, Y., McQuade, T., Zhang, H., Zhang, J. \& Chan, F.K.-M. RIP1dependent and independent effects of necrostatin- 1 in necrosis and Tcell activation. PLoS One 6, e23209 (2011).

147. Doz, E. et al. Cigarette smoke-induced pulmonary inflammation is TLR4/MyD88 and IL-1R1/MyD88 signaling dependent. J. Immunol. 180, 1169-1178 (2008).

148. Maes, T., Bracke, K.R., Joos, G.F. \& Brusselle, G.G. Comment on 'Cigarette smoke-induced pulmonary inflammation is TLR4/MyD88 and IL-1R1/MyD88 signaling dependent'. J. Immunol. 180, 5761 (2008). 